\title{
Melanoma and skin cancers in psoriatic patients treated with phototherapy. Role of the p16 protein in psoriasis
}

\author{
Anna Szponar-Bojda ${ }^{1}$, Aldona Pietrzak ${ }^{2}$, Agnieszka Sobczynska-Tomaszewska ${ }^{3}$, \\ Adam Borzecki ${ }^{1}$, Andrzej Kurylcio ${ }^{4}$, Wojciech Polkowski ${ }^{4}$, \\ Anna Poluha5, Grazyna Chodorowska ${ }^{2}$ \\ ${ }^{1}$ Non-Public Health Care Center Med-Laser, Lublin, Poland \\ ${ }^{2}$ Department of Dermatology, Venerology and Pediatric Dermatology, \\ Medical University of Lublin, Poland \\ ${ }^{3}$ Health Care Center Genomed, Warsaw, Poland \\ ${ }^{4}$ Department of Surgical Oncology, Medical University of Lublin, Poland \\ ${ }^{5}$ Department of Pediatric Hematology and Oncology, Bone Marrow Transplantation Unit, \\ Medical University of Lublin, Poland
}

\begin{abstract}
Recently, the potential risk of malignant cancer development in psoriatic patients has been highlighted. However, the relationship between the therapeutic schemes in psoriasis and possible neoplastic transformation has not been so far clearly explained. Phototherapy is considered a very effective therapeutic method in psoriasis, however, the pathogenesis of some malignancies may be associated with the exposure to UV radiation. p16 protein belongs to the defense mechanisms that protect cells from damage and mutagenic factors, such as UV radiation. In recent years, the altered expression of the p16 protein in the diseases not related to malignant transformation, including psoriasis, has been observed. These new observations suggest participation of the p16 protein in the mechanisms of psoriatic plaque formation. (Folia Histochemica et Cytobiologica 2012, Vol. 50, No. 4, 491-496)
\end{abstract}

Key words: melanoma, SCC, BCC, psoriasis, p16, PUVA, UVB, phototherapy

\section{Introduction}

Melanoma is a malignant tumor derived from melanocytes, neuroectodermal cells producing melanin and located in the basal layer of the epidermis. Worldwide, each year 133,000 melanoma skin cancers occur, of which approximately $80 \%$ appear in North America (the 6th country for morbidity), Europe, Australia and New Zealand [1]. Recently, a signifi-

Correspondence address: A. Szponar-Bojda,

Non-Public Health Care Centre Med-Laser,

Mlynska St. 14A, 20-406 Lublin, Poland;

e-mail: anna.szponar@wp.pl cant increase in melanoma incidence among Caucasians has been observed $[1,2]$.

An impaired DNA repair system and chronic exposure to exogenous mutagenic agents can result in the development of this cancer. Poland is a country with a relatively low incidence of melanoma -4 persons per 100,000 residents [1, 2]. In 2005, 2,190 new cases of disease and 906 deaths from melanoma were registered [1]. According to the standarized incidence ratios, melanoma takes the 16th place among men's and 15th among women's ilnesses. Since the 80s of the last century, a steady increase in the incidence ratio of melanoma in both sexes $(10 \%$ in men, $8 \%$ in women) has been observed, which illustrates the increased risk of the disease and deaths from melano- 
ma. According to the standarized mortality ratios, melanoma is on the 16th place between neoplasms in men and 17 th one in women $[1,2]$.

The pathogenesis of melanoma and factors involved in its development have not been fully explained yet. Some environmental and genetic factors as well as immunosuppression and familiar incidence of melanoma are known to be important risk factors. The increased incidence affects people with a high socio-economic status $[1,3]$.

The intensity of ultraviolet radiation exposure (UVA and UVB) and cumulative dose effect are considered the main risk factors of melanoma (environmental and suppressive) [1]. The role of chronic immunosuppression in organ transplant recipients (more than three-fold increased risk) and coexistence of xeroderma pigmentosum have been highlighted $[1,3]$.

The re-development of melanoma can occur in $5-10 \%$ of the previously cured patients. It could be related to the presence of a large number of naevi, particularly atypical and familiar incidence (dysplastic naevus syndrome) $[1,3]$.

A clinical diagnosis of melanoma is based on the medical history and the examination. Specific diagnostic systems can be helpful in evaluating the clinical symptoms of disease. ABCDE system (for early melanomas) evaluates the asymmetry of changes, border irregularity, color, diameter, elevation above the level of the epidermis [1]. Glasgow system (for locally advanced melanomas) evaluates seven features: change in size, irregular shape, colour, diameter $>7 \mathrm{~mm}$, inflammation, oozing or bleeding, change in sensation [1]. The dermoscopy plays an increasing role in the differential diagnosis of melanoma and improves diagnostic sensitivity to $27 \%$ [1].

There are four histological types of melanoma [3]: 1) superficial spreading melanoma (50-70\% of cases);

2) nodular melanoma (10-15\%);

3) lentigo maligna melanoma (5\%);

4) acral lentiginous melanoma (2-10\%).

The evaluation of the clinical stage of melanoma is based on the TNM system. In 2009, the American Joint Committee On Cancer (AJCC) revised the TNM staging system for cutaneous melanoma [4].

\section{The role of the $\mathrm{p} 16$ protein in psoriasis and neoplastic transformation}

The p16 protein, encoded by the $C D K N 2 A$ gene (MIM: 600160) located on chromosome 9p21 has been identified as a melanoma susceptibility marker (Figure 1). The impaired expression of this protein affects the life cycle of cells, significantly contributing to neoplastic transformation. The $C D K N 2 A$ gene

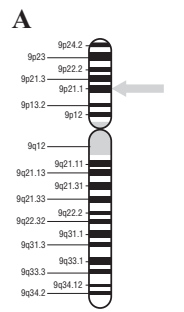

B

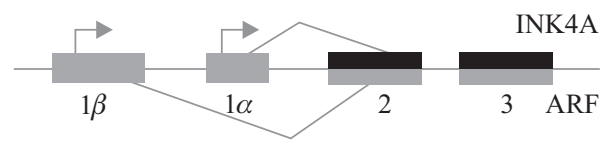

Figure 1. The $C D K N 2 A$ gene scheme. (A) Chromosomal position of the gene; (B) The $C D K N 2 A$ gene organisation.Gene contains two upstream exons, $1 \alpha$ and $1 \beta$. Expression of these two exons are regulated by separate promoters, which result in alternative transcripts and distinct translation products: INK4A and ARF

encodes proteins that regulate two critical cell cycle regulatory pathways, the p53 (TP53; MIM: 191170) pathway and the RB1 (MIM: 614041) pathway. Through the use of shared coding regions and alternative reading frames, the $C D K N 2 A$ gene produces 2 major proteins: p16(INK4), which is a cyclin-dependent kinase inhibitor, and p14(ARF), which binds the p53-stabilizing protein MDM2 (164785) [5]. The p16 protein regulates the cell cycle in the G1/S phase, acting as an inhibitor of the cyclin-dependent kinase D (CDK) through inactivation of the retinoblastoma susceptibility gene product - RB1 protein, having a pivotal role in the late G1 phase restriction point [6]. Deficiency of this protein leads to hyperphosphorylation of RB1, resulting in the increased release of E2F transcription factor and uncontrolled cell cycling [7]. The p16 protein has been also regarded as a marker for cellular senescence [8-11]. The second regulatory protein, $\mathrm{p} 14$, with the antiproliferative activity, regulates the cell cycle at the G1/G2 transition point and is responsible for the stabilization of $\mathrm{p} 53$. The undisturbed expression of p53 leads to the cell cycle arrest at the $\mathrm{G} 2 / \mathrm{M}$ transition phase or to apoptosis when the cell is exposed to damaging factors. The frequent deletions or mutations of the $C D K N 2 A$ in tumor cells suggests that p16 acts as a tumor suppressor. Deletions or mutations in the p16 gene may affect the relative balance of functional p16 and cyclin $\mathrm{D}$, resulting in abnormal cell growth. The CDKN2A gene alterations occur also frequently in pancreatic adenocarcinoma, esophageal and gastric cancers, bladder cancer, leukemia and others.

In recent years, the altered expression of the $\mathrm{p} 16$ protein in the diseases not related to malignant transformation, including psoriasis, has been observed [8]. The new hypothesis suggesting a participation of the p16 protein in psoriatic plaque formation has appeared [12]. 
The hyperproliferation of keratinocytes caused by excessive cell division in the basal layer of the epidermis and shortening of the skin cells cycle are considered the key processes in the pathogenesis of psoriasis $[13,14]$. These changes could be accompanied by the vascular disorders - increased angiogenesis within the prolonged dermal papillae and the infiltration by $\mathrm{T}$ lymphocytes [15]. The immunological processes in psoriasis are associated with the increased activity of the helper T cells (Th1 response) and production of pro-inflammatory cytokines such as tumor necrosis factor $\alpha$ (TNF- $\alpha)$, interferon- $\gamma$ (IFN- $\gamma)$, interleukin 2 (IL-2), and interleukin 6 (IL-6) [16]. It is well known that the Th-dependent cytokines stimulate proliferation of keratinocytes and the release of other interleukins which result in a cascade of mediators responsible for the development of psoriasis [17, 18].

The hyperproliferation of the keratinocytes has long been considered the dominant pathogenetic process in plaque formation [13, 14]. As Nickoloff et al. stated, keratinocytes' hyperplasia occurs primarily in the basal layers of the epidermis, while keratinocytes in the middle and upper layers follow an aberrant differentiation pathway and resist apoptosis and transformation, features that resemble the state of cellular senescence $[8,19]$. As suggested by Wrone-Smith et al., this phenomenon is equally involved in psoriatic plaque formation due to the presence of keratinocytes which have failed to undergo programmed cell death [12]. According to many authors, these observations may explain the oncogenic potential in patients with psoriasis. It has been shown that senescence keratinocytes in the middle and upper layers of the epidermis are resistant to apoptosis $[12,20]$ and neoplastic transformation $[14,19]$. Enhanced p16 expression with the antiapoptotic activity within psoriatic plaque reported by some authors, seems to confirm this hypothesis $[8,11,21]$.

However, many authors have published divergent reports on the $\mathrm{p} 16$ protein expression in the psoriatic skin. Mark et al. showed low expression of the p16 encoding gene in the psoriatic plaques as well as in normal skin [22]. Abou et al. studied the effect of phototherapy on the p16 expression and found that significantly less protein in psoriatic lesions were observed before phototherapy than in controls. Moreover, they confirmed the stimulating effect of phototherapy on the synthesis of the p16 in the skin [24]. In contrast, Elias et al. showed elevated levels of the p16 protein in psoriatic plaque [21]. The increased p16 protein levels in psoriatic lesions have also been reported in the study of Chaturvedi et al. [11]. The observed differences in the published data for the p16 gene expression could result from different localiza- tion of psoriatic lesions, various age of the plaques and individual features of patients [22].

It is possible that during psoriatic plaque formation an imbalance between the proliferation and induction of senescence in the keratinocytes occurs [22]. At the early stage of the formation of psoriatic plaques, the proliferating keratinocytes might not show the increased p16 expression, while the majority of the cells of the upper layer of psoriatic epidermis becomes arrested in the G1 phase in a state termed replicative senescence, induced by the overexpression of the p16 protein [22, 23]. According to Abou et al., the altered expression of cell-cycle regulatory genes, including the p16, may play a significant role in the pathogenesis of hyperproliferative diseases. The detected decreased level of the p16 indicates a shift of balance toward proliferative rather than senescent processes, which could have an impact on the etiopathogenesis of psoriasis [24].

The induction of the p16, responsible for the senescence-switch of keratinocytes, has been suggested to reflect one of the defense mechanisms that protect the cells from damaging and mutagenic factors, such as UV radiation [22]. The cells manifesting the up-regulation of the tumour suppressor p16 seem to be relatively resistant to malignant transformation [25]. Wrone-Smith et al. showed that cells from psoriatic skin presented delayed apoptosis in response to UV exposure [12].

\section{PUVA therapy and phototherapy in psoriasis: pros and cons}

Recently, the potential risk of malignant transformation in psoriatic patients has been taken under consideration. This could be related both to the pathogenesis of psoriasis, phenotype of psoriatic plaque and the therapeutic methods associated with the prolonged immunosuppression and exposure to mutagenic agents, widely used in this group of patients. The phenomena observed in psoriasis, such as chronic inflammation, epidermal hyperplasia, neoangiogenesis and the prolonged survival of psoriatic lesions could predispose to a malignant transformation $[8,26]$.

So far, the relationship between the therapeutic schemes in psoriasis and possible neoplastic transformation has not been clearly explained. The phototherapy is considered a very effective therapeutic method in psoriasis, however, the pathogenesis of some malignancies is associated with the exposure to UV radiation.

Since 1974, the photochemotherapy with oral psoralens and UVA radiation (PUVA) has been one of the most widespread, highly effective methods of 
treatment in psoriasis [27]. The PUVA therapy intercalates into the DNA double helix and generates highly mutagenic photoproducts which damp the rapidly dividing psoriatic epidermis down [28]. However, the immunosuppressive effects of UV radiation can contribute to malignant transformation [29-32].

Stern et al. studied a group of 1380 patients with psoriasis treated in 1975-1976 with PUVA. The results showed 100-fold increase in the risk of squamous cell cancer (SCC) compared to that expected from the popular incidence rates [33]. An exposure to PUVA had a far smaller effect on the risk of basal cell carcinoma (BCC). It was suggested that the risk of SCC was highly dose-related: the incidence among patients exposed to more than $2000 \mathrm{~J} / \mathrm{cm}^{2}$ or 200 exposures was 14-fold higher than among patients with a low-dose exposure $\left(<1000 \mathrm{~J} / \mathrm{cm}^{2}\right.$ or 100 exposures) [34].

Although the literature data report cases of melanoma in patients treated with PUVA, the correlation between the UVA exposure and malignant transformation seems to be controversial [35,36]. It was suggested that PUVA stimulate the growth of melanoma cells $[37,38]$. The results of Alcalay et al. have shown a close relationship between PUVA radiation exposure and melanocytic tumor development in mouse [37]. Aubin et al. demonstrated that PUVA treatment can contribute to the pathogenesis of melanoma by exerting a stimulatory effect on the growth of melanoma cells [38]. However, in the 1990s, large cohort studies of the PUVA-treated patients failed to detect an increased risk of melanoma [36, 39, 40]. Swedish researchers had observed a group of 4799 psoriasis patients for 16 years and did not find an increased risk of melanoma in PUVA-treated subjects [41, 42]. According to many authors, the increased risk of melanoma development is tightly associated with the level of PUVA exposure, a cumulative dose of the UVA radiation and the latency period. Stern et al. highlighted that patients who received at least 250 treatments in a period of at least 15 years after the first PUVA treatment are more likely to develop melanoma [43].

Recently, the UVB phototherapy has partly replaced the PUVA therapy. Two separate modalities of the UVB phototherapy can be distinguished - the broadband therapy (BB UVB), available for more than 80 years and the newer narrowband UVB (NB UVB) with the radiation emission at $311 \mathrm{~nm}$. NB UVB has been shown to be superior to BB UVB for a number of dermatoses [28, 44]. The UVB phototherapy is widely considered as a safer alternative to the PUVA therapy [45]. The retrospective study of Man et al. [46] on a group of 1908 patients treated with UVB311 phototherapy showed no increased risk of melanoma and SCC in these patients. However, 10 patients developed BCC compared with an expected 4.7 in the Scottish population: in this group of patients, BCCs have appeared during the first 3 months of therapy and probably had no relationship with the treatment [46]. In 2005, the analysis from the PUVA follow-up study detected 7-fold higher risk of malignant transformation in patients treated with PUVA in comparison with the NB UVB therapy [47]. On the contrary, in 2008, Hearn et al. found no significant association between NB UVB treatment and BCC, SCC or melanoma [48].

In the context of these reports, a key finding is that cutaneous malignancies such as melanoma, SCC and BCC develop in contiguity with psoriatic plaques extremely rarely [8]. Moreover, some authors suggested a protective role of such pathogenic factors as inflammatory cytokines in psoriasis against melanogenesis, melanocyte growth and progression to naevi. As Balato et al. reported [49], patients with psoriasis presented a lower number of naevi in comparison with controls. Moreover, not a single patient with psoriasis had ever had melanoma or SCC [49]. In 2000, the first case report of melanoma developing in psoriatic plaque was published [50]. In literature, there are no reports of a psoriatic plaque developing into SCC or BCC [8]. The cutaneous malignancies in psoriasis patients have always occured in uninvolved skin.

\section{Conclusions}

On the basis of provided data it can be concluded that increased p16 expression and replicative senescence switch can represent a novel model of cell protection in clinical practice. However, it is important to mention that a reverse phenomenon has been reported in melanoma [51] and the preinvasive and invasive SCC [52], namely, the inactivation of the $p 16$ gene. The $C D K N 2 A$ mutations, like homozygous deletion, rearrangments, hypermethylation or point mutations result in the p16 underexpression. In the light of recent studies, a decreased p16 level could be highly disadvantageous in psoriasis. A low level of p16 may contribute to epidermal proliferation and be involved in the pathogenesis of psoriasis [22, 24]. Moreover, it seems that the p16 plays an important role in cell defense against mutagenic agents and could be responsible for the delayed apoptosis and the relative resistance to malignant transformation [12, 25]. Nowadays, the therapeutic schemes in psoriasis might increase the risk of cutaneous malignant transformation e.g. by DNA damage due to phototherapy [22]. Underexpression of the $\mathrm{p} 16$ as a consequence of $C D K N 2 A$ mutation could increase susceptibility to 
malignant transformation during routine treatment of psoriasis.

In patients with many dysplastic naevi, suffering from psoriasis, the possibility of the $p 16$ gene mutations should be considered when qualifying for phototherapy. Application of retinoids and cygnoline in the areas with naevi should be avoided. Psoriatic patients with a positive family history of melanoma and the incidence of dysplastic naevi should be routinely screened for possible p16 mutations before phototherapy.

\section{Acknowledgment}

The writing of this manuscript was supported by funding from the Medical University of Lublin, Poland (grant DS 168/2012).

\section{References}

1. Ruka W, Nowecki ZI, Rutkowski P. Melanomas of skin in adults. Medipage, London 2005.

2. Wojciechowska U, Didkowska J, Tarkowski W, Zatonski W. Cancer in Poland in 2004. Maria Sklodowska-Curie Institute of Oncology, Warsaw 2006.

3. Garbe C, Peris K, Hauschild A et al. Diagnosis and treatment of melanoma. European consensus-based interdisciplinary guideline - Update 2012. Eur J Cancer. 2012; 48:2375-2390 .

4. Piris A, Lobo AC, Duncan LM. Melanoma staging: where are we now? Dermatol Clin. 2012;30:581-592.

5. Robertson KD, Jones PA. Tissue-specific alternative splicing in the human INK4a/ARF cell cycle regulators locus. Oncogene. 1999;18:3810-3820.

6. Gabrielli BG, Saracevic B, Sinnamon J et al. A cyclin D-CDK4 activity required for $\mathrm{G} 2$ phase cell cycle progression is inhibited in ultraviolet radiation-induced G2 phase delay. $J$ Biol Chem. 1999;274:13961-13969.

7. Sekulic A, Haluska P Jr, Miller AJ et al. Malignant melanoma in the 21st century: the emerging molecular landscape. Mayo Clin Proc. 2008;83:825-846.

8. Nickoloff BJ. Creation of psoriatic plaques: the ultimate tumor suppressor pathway. A new model for an ancient T-cell-mediated skin disease. Viewpoint. J Cutan Pathol. 2001; 28:57-64.

9. Hara E, Smith R, Parry D et al. Regulation of p16 expression and its implications for cell immortalization and senescence. Mol Cell Biol. 1996;16:859-867.

10. Stein GH, Drullinger LF, Soulard A, Dulice V. Differential roles for cyclin-dependent kinase inhibitors p21 and pl6 in the mechanisms of senescence and differentiation in human fibroblasts. Mol Cell Biol. 1999;19:2109-2117.

11. Chaturvedi V, Cesnjaj M, Bacon P et al. Role of INK4a/Arf locus-encoded senescent checkpoints activated in normal and psoriatic keratinocytes. Am J Pathol. 2003;162:161-170.

12. Wrone-Smith T, Mitra RS, Thompson CB, Jasty R, Castle VP, Nickoloff BJ. Keratinocytes derived from psoriatic plaques are resistant to apoptosis compared with normal skin. Am J Pathol. 1997;150:1321-1329.

13. Weinstein GD, Frost P. Abnormal cell proliferation in psoriasis. J Invest Dermatol. 1968;50:254-259.

14. Nickoloff1 BJ. The immunological and genetic basis of psoriasis. Arch Dermatol. 1999;135:1104-1110.
15. Bos JD, de Rie MA, Teunissen MBM, Piskin G. Psoriasis: dysregulation of innate immunity. Br J Dermatol. 2005;152: 1098-1107.

16. Gearing AJ, Fincham NJ, Bird CR et al. Cytokines in skin lesions of psoriasis. Cytokine. 1990;2:68-75.

17. Prens EP, Benne K, van Damme J et al. Interleukin-1 and interleukin-6 in psoriasis. J Invest Dermatol. 1990;95 Suppl 6:121S-124S.

18. Nickoloff BJ, Rifle GD, Barker JNWN et al. Localization of interleukin-8 and its inducer, tumor necrosis factor-alpha in psoriasis. Am J Pathol. 1991;138:129-140.

19. Nickoloff 2 BJ. Skin innate immune respon se in psoriasis: friend or foe? J Clin Invest. 1999;104:1161-1164.

20. Chaturvedi V, Qin JZ, Denning MF, Choubey D, Diaz MO, Nickoloff BJ. Apoptosis in proliferating, senescent and immortalized keratinocytes. J Biol Chem. 1999,274:23358-23367 .

21. Elias AN, Barr RJ, Nanda VS . p16 expression in psoriatic lesions following therapy with propylthiouracil, an antithyroid thioureylene. Int J Dermatol. 2004;43:889-892.

22. Mark EB, Jonsson M, Asp J, Wennberg AM, Mölne L, Lindahl A . Expression of genes involved in the regulation of p16 in psoriatic skin involved. Arch Dermatol Res. 2006;297: 459-467.

23. Lundberg AS, Hahn WC, Gupta P, Weinberg RA . Genes involved in senescence and immortalization. Curr Opin Cell Biol. 2000;12:705-709.

24. Abou El-Ela M, Nagui N, Mahgoub D et al. Expression of cyclin D1 and p16 in psoriasis before and after phototherapy. Clin Exp Dermatol. 2010;35:781-785.

25. Nickoloff BJ . The skin cancer paradox of psoriasis: a matter of life and death decisions in the epidermis. Arch Dermatol. 2004;140:873-875.

26. Cordon-Cardo C, Prives C. At the crossroads of inflammation and tumorigenesis. J Exp Med. 1999;190:1367-1370.

27. Parrish JA, Fitzpatrick TB, Tanenbaum L, Pathak MA. Photochemotherapy of psoriasis with oral methoxsalen and long wave ultraviolet light. N Engl J Med. 1974;291:1207-1211.

28. Patel RV, Clark LN, Lebwohl M Weinberg JM. Treatments for psoriasis and the risk of malignancy. J Am Acad Dermatol. 2009;60:1001-1017.

29. Berneburg M, Krutmann J. Photoimmunology, DNA repair and photocarcinogenesis. J Photochem Photobiol. 2000;54:87-93.

30. Kripke ML. Antigenicity of murine skin tumors induced by ultraviolet light. J Natl Cancer Inst. 1974;53:1333-1336.

31. Kripke ML. Immunology of UV radiation. Mechanisms in carcinogenesis. Adv Cancer Res. 1981;34:69-106.

32. Schwarz T. Effects of ultraviolet radiation on immunity.J Dtsch Dermatol Ges. 2003;2:142-150.

33. Stern RS, Liebman EJ, Vakeva L. Oral psoralen and ultraviolet-A light (PUVA) treatment of psoriasis and persistent risk of non-melanoma skin cancer. J Natl Cancer Inst. 1998;90:1278-1284.

34. Stern RS, Lunder EJ . Risk of squamous cell carcinoma and methoxsalen (psoralen) and UV-A radiation (PUVA). A meta-analysis. Arch Dermatol. 1998;134:1582-1585.

35. Bergner T, Przybilla B. Malignant melanoma in association with phototherapy. Dermatology. 1992;184:59-61.

36. Gupta AK, Stern RS, Swanson NA, Anderson TF. Cutaneous melanomas in patients treated with psoralens plus ultraviolet A: a case report and the experience of the PUVA Follow-up Study. J Am Acad Dermatol. 1988;19:67-76.

37. Alcalay J, Bucan C, Kripke ML. Cutaneous pigmented melanocytic tumor in a mouse treated with psoralen plus ultravi- 
olet A radiation. Photodermatol Photoimmunol Photomed 1990; 7:28-31.

38. Aubin F, Donawho CK, Kripke ML. Effect of psoralen plus ultraviolet A radiation on in vivo growth of melanoma cells. Cancer Res. 1991;51:5893-5897.

39. Henseler T, Christophers E, Hönigsmann H, Wolff K. Skin tumors in the European PUVA Study: eight-year follow-up of patients treated with 1.643 PUVA for psoriasis. J Am Acad Dermatol. 1987;16:108-116.

40. Lindelof B, Sigurgeirsson B, Tegner E, et al. PUVA and cancer: a largescale Epidemiological study. Lancet. 1991;338:91-93.

41. Lindelof B, Sigurgeirsson B, Tegner E et al. PUVA and cancer risk: the Swedish follow-up study. Br J Dermatol. 1999;141:108-112.

42. Koo JYM, Fitzpatrick TB, Krueger G, et al. PUVA phototherapy: assessing and optimizing the risk/benefit ratio. Skin Allergy News Supp. 2001;32:1-15.

43. Stern RS, Nichols KT, Vakeva LH. Malignant melanoma in patients treated for psoriasis with methoxsalen (psoralen) and ultraviolet A radiation (PUVA). N Engl J Med.1997;336: 1041-1045.

44. Lapolla W, Yentzer BA, Bagel J et al. A review of phototherapy protocols for psoriasis treatment. J Am Acad Dermatol. 2011;64:936-49.

45. Stern RS, Laird N. The carcinogenic risk of severe psoriasis treatments for cancer. Photochemotherapy Follow-up Study. Cancer. 1994;73:2759-2764.
46. Man I, Crombie IK, Dawe RS, Ibbotson SH, Ferguson J. The photocarcinogenic risk of narrowband UVB (TL-01) phototherapy: early follow-up data. Br J Dermatol. 2005;152: 755-757.

47. Lim JL, Stern RS. High levels of ultraviolet B exposure increase the risk of non-melanoma skin cancer in psoralen and ultraviolet A-treated patients. J Invest Dermatol. 2005;124: 505-513.

48. Hearn RM, Kerr AC, Rahim HF, Ferguson J, Dawe RS. Incidence of skin cancers in 3867 patients treated with narrowband ultraviolet B phototherapy. Br J Dermatol. 2008;159: 931-935.

49. Balato N, Di Costanzo L, Balato A, Patruno C, Scalvenzi M, Ayala F. Psoriasis and melanocytic naevi: does the first confer a protective role against the progression of melanocyte naevi? Br J Dermatol. 2011;164:1262-1270.

50. Tran N, Rabinovitz HS, Oliviero M, Kopf A. Melanoma in a psoriatic plaque. Cutis. 2000;65:93-94.

51. Monzon J, Liu L, Brill H et al. CDKN2A mutations in multiple primary melanomas. N Engl J Med. 1998;338:879-887.

52. Reed AL, Califa J, Cairns P et al. High frequency of p16 (CDKN2/MTS-1/INK4A) inactivation in head and neck squamous cell carcinoma. Cancer Res. 1996;56:3630-3633.

53. Quelle DE, Zindy F, Ashmun RA, Sherr CJ. Alternative reading frames of the INK4a tumor suppressor gene encode two unrelated proteins capable of inducing cell cycle arrest. Cell 1995;83:993-1000.

Submitted: 12 February, 2012

Accepted after reviews: 4 November, 2012 